

\title{
MEASUREMENT OF THE LOCAL PARTICLE DIFFUSION COEFFICIENT IN A MAGNETIZED \\ PLASMA
}

\author{
PPPL -2411 \\ D.D. Meyerhofer ${ }^{1}$ and F.M. Levinton ${ }^{2}$ \\ DE87 008072 \\ Plasma Physics Laboratory, Princeton University \\ P.O. Box 451 Princeton, NJ 08544
}

\begin{abstract}
Local impurity particle diffusion coefficients have been measured in a low temperature plasma by the injection of test particles at the center of the plasma. The injection is accomplished by a high voltage discharge between two small graphite electrodes on a probe. The probe can be located anywhere in the plasma. The diffusion is observed spectroscopically. An analysis of the spatial and temporal evolution of the CII radiation from the carbon discharge can determine the parallel and perpendicular diffusion of the impurity ions. Results with the diagrostic have been obtained in the Proto S-1/C spheromak. The measured value of the diffusion coefficient in the afterglow plasma is in good agreement with classical predictions.
\end{abstract}

${ }^{1}$ Present Address: Lab of Plasma Studies, Upson Hall, Cornell University, Ithaca, NY 14853

${ }^{2}$ On Assignment from JAYCOR, Torrance, CA 90503 


\section{Introduction}

Measurement of the loc:: particle diffusion coefficient is essential toward an understanding of the transport processes in a laboratory confined plasma. In order to abtain an understanding of the driving mechanisms of the transport, it is helpful to measure the local particle diffusion coefficient and correlate it with the plastna parameters, including fluctuations in the density, and electric and magnetic fields.

To measure the particle diffusion in the Proto S-1/C spheromak, a diagnostic that not only provides spatial, but also good temporal resolution is required. This is needed because of the short lifetime of the experiment $(100 \mu \mathrm{sec})$ and large particle diffusion rates due to the low temperatures $(5 \sim 15 \mathrm{eV})$, low magnetic fields $(1 \sim 3 \mathrm{kG})$, and high electron densities $\left(0.5 \sim 2 \times 10^{14} \mathrm{~cm}^{-3}\right)$.

Various methods have been used to measure the particle confinement time, $\tau_{p}$, or diffusion coefficient, in fusion plasma experiments. Most of these methods would not be appropriate in Proto S-1/C because of the spatial and temporal resolution required.

A common methad is to measure the $H_{\alpha}$ radjation from the plasma with an absolutely calibrated spectrometer. ${ }^{2,3}$ There is significant density outside the separatrix in Proto S$1 / \mathrm{C}$ which contributes to the $H_{a}$ radiation. In addition, the lack of spatial uniformity in the signal makes interpretation of $\tau_{p}$ difficult.

On the PLT ${ }^{4}$ and $\mathrm{T}-10^{5}$ tokamaks the information gained from the $H_{\alpha}$ has been augmented by gas puffing. On PLT the evolution of the density profile after a gas puff is used to estimate the diffusion coefficient and convective velocities. On T-10, a single gas puff has been augmented by periodic puffing which allows phase correlations between the density changes at various locations to be measured.

A number of methods for determining $\tau_{p}$ rely on the use of computer codes(e.g., the MIST code ${ }^{6}$ ) to solve impurity ionization, recombination, and transport models. The injection of an impurity from the edge of the plasma by laser blowoff is the most common of these techniques, ${ }^{7,8}$ In this case, an impurity species which is typically not found in 
the plasma is chosen. The lemporal and spatial evolution of the various charge states of the impurity ions is followed spectroscopically, and these results are compared with those generat ed in an impurity evolution computer code. The measured temperature and density profiles are used as input in the code and the particle diffusion coefficient and convective velocity are the major free parameters so that the global particle diffusion coefficient can be determined by matching the observations. This method has two difficulties for application to Proto S-1/C. Firstly, the injected impurities are neutral and have a transit time which is longer than the diffusion time scale in this experiment. Secoudly, injection of the impurities from the edge makes the interpretation of the local particle diffusion difficult.

A similar estimate of the diffusion coefficients can be made if the profiles of the impuritjes can be determined. By the use of charge-exchange recombination spectroscopy, the radial profiles of all of the charge states of a low- $Z$ impurity species(i.e., oxygen) can be determined. ${ }^{9}$ Again, with a knowledge of the temperature and density profiles, an impurity transport code can be used to determine the particle diffusion coefficient.

In addition to the schemes described above, a number of other spectroscopic techniques have been devised to follow the evolution of test particles to determine the confinement properties, such as the method described in this article. These include optical tagging, ${ }^{10}$ the use of high energy electrons, ${ }^{11}$ injection of a gas puff tlırough a hollow tube, ${ }^{12}$ and the injection of neutral impurities by laser ablation of a pellet in the plasma. ${ }^{13}$ The first two of these techniques require knowledge of the magnetic flux surfaces to separate parallel and perpendicular diffusion. The latter two techniques inject neutral atoms so that the source of ions, the useful test particles, is unknown and requires knowledge of the local plasma parameters. The time scale for changes in the plasma parameters is significantly shorter than the discharge lifetime making these measurements even more difficult.

The most commonly usec' methods for determining the particle diffusion coefficients would be difficult to implement on Proto S-1/C so a novel method of measuring the local parallel and perpendicular particle diffusion coefficients has been developed and will be described in the next section. 


\section{Experimental Technique}

The basic technique used to measure the particle diffusion coefficient is to inject a delta function(in both space and time) source of particles into the spheromak plasma and spectroscopically observe them as they move across flux surfaces. Figure 1 shows the basic layout of the experiment. A probe, consisting of a pair of carbon tips connected to a capacitor, is inserted into the midplane of the plasma. The capacitor is discharged on a time scale short compared to the plasma lifetime and the injected carbon is observed spectroscopically. The geometry of Proto S-1/C, with a $48 \mathrm{~cm}$ diameter, allows a large glass window $(35 \mathrm{~cm}$ diameter) to be installed on the end of the machine in a constant $z$ plane. A visible spectrometer is comnected to a morable lens assembly on the outside of the window by a fiber optic cable. The system is focused onto the midplane of the plasma.

The perpendicular particle diffusion coefficient, $D_{\perp}$, is measured by moving the viewing location of the spectroneter radially from the injection point, thus observing the diffusion of the injected particles across the flux surface. The diffusion of particles parallel to the magnetic field, $D_{\|}$, can be observed by rotating the lens and fiber optic assembly toroidally away from the discharge. The lens assembly is also adjusted in the major radius direction due to the rotation of the inagnetic flux tube. This providis a measure of the local rotational transform, or $q$.

\section{A. Experimental Setup}

The injection source (Fig. 2) consists of a pair of graphite rods, $3 \mathrm{~mm}$ in diameter, which have been machined into a mushroom shape and are connected by stainless steel sleeves to an RG58 coaxial cable. The inner diameter of the stainiess steel sleeves is slightly less than the diameter of the carbon rods. The sleeves are heated and slipped over the carbon to obtain a good electrical contact . The entire cable is enclosed in a $3 / 8$ in. o.d. stainless steel tube. A vacuum seal is obtained with a silicon sealant which is flexible enough to withstand the forces caused by the firing of the spark and maintain a good vacuum seal. Figure 3 is a photograph of the tips of the electrodes after substantial use. 
The coaxial cable from the electrodes is connected to a $15 \mathrm{kV}, 2 \mu \mathrm{F}$ capacitor. Typically: the capacitor is charged to $12 \mathrm{kV}$ and is discharged by firing an ignitron. Figure 4 shows an example of the current in the circuit, with a peak current of $6 \mathrm{kA}$. The inductance of the system is determined from the width of the current pulse, and is roughly $2 \mu \mathrm{H}$, with half of the inductance in the firing circuit and half in the cable and tips.

The spectrometer is a $0.5 \mathrm{~m}$ Czerny-Turner Monochromator with a $1200 \mathrm{~g} / \mathrm{mm}$ grating. Light is collected by a lens and imaged onto a quartz fiber optic bundle which couples the light to the monochromator. The fiber optic bundle consists of a row of 210 micron fibers. The lens and fiber optic assembly is free to move along the major radius and can be rotated toroidally. This allows sufficient freedom to view any location in the plasma. A $1 \mathrm{~mm}$ slit in front of the fiber guide gives a $2 \mathrm{~mm}$ resolution in the plasma.

\section{B. Details of the Injection}

The initial conditions of the injected partjeles are determined by looking in the vicinity of the discharge, both spatially and temporally. Distance from the injection discharge will be defined as $\Delta r$, with the positive direction taken to be in the direction of positive major radius.

As shown in Fig. 4, the peak current during the discharge is roughly $6 \mathrm{kA}$. The path of the current due to the disch arge is roughly that of a $2 \mathrm{~mm}$ diameter loop, as the currents are cancelled, except in the neighborhood of the spark. The peak magnetic field caused by the discharge current is roughly $20 \mathrm{kG}$ at the axis of the loop. While this current falls off as $r^{3}$, it is still a significant local perturbation of the magnetic field which is an order of magnitude lower. For this reason, the initial condition for the density evolution is chosen as the shape of the injected impurities at the end of the injection discharge as shown in Fig. 5. The line drawn through the points is a gaussian, $e^{-\tau^{2} / r_{0}^{2}}$, with $r_{0}=0.6 \mathrm{~cm}$. Thus. the changes in the density evointion are observed after the largest perturbations from the carbon discharge are over. At this point the increase of the local carbon density is less than a factor of two. 


\section{Basic Assumptions}

A variety of assumptions are required to interpret the spatial expansion of the injected carbon. Experimentally it is observed, from the parallel motion of the injected carbon ions, that it would take longer than the discharge lifetime for the carbon to spread over the flux surface. Thus, the motion of the injected carbon is determined by the locai magnetic field and not the full magnetic flux surface. It is assumed that the local magnetic flux tube can be approximated by a cylindrical geometry with the symmetry axis(the $\vec{z}$ direction) along the magnetic field, and that two diffusion coefficients will be sufficient to describe the evolution of the injected carbon density, $D_{\|}$along the local magnetic field and $D_{\perp}$ in the directions orthogonal to the feld. This ignores any differences between the diffusion in the flux surface perpendicular to the magnetic field and perpendicular to the surface.

In a magnetized plasma cross-field diffusion is driven by collisions between different species. By conservation of momentum, collisions between like particles cannot drive diffusion. ${ }^{14}$ The carbon diffusion in the background plasma is driven by the carbon-hydrogen collisions. The momentum acquired in these collisions moves the carbon gujding center an average distance of the ion gyro-radius, $\rho_{L}$. Because of the density gradient, there is a net flux of particles down the density gradient, $D_{\perp} \sim \rho_{L}^{2} / 2 \tau_{\mathrm{CH}}$, where $\tau_{\mathrm{CF}}$ is the carbon-hydrogen collision time.

In the Proto $5-1 / C$ plasmas, the gradient length of the injected carbon density and the time scale for the change in the injected carbon density are shorter than those of the background plasma. It is assumed that the diffusion coefficient is constant in the region of the measurement and in time, and that the carbon density gradient drives the diffusion.

While all of the carbon is initially in the CII charge state, there is some ionization into the CIII charge state. This effect has been included and is discussed in Sec. III 


\section{Solution of the Continuity Equation}

In a cylindrical coordinate system the impurity density evolution is governed by

$$
\frac{\partial n(\vec{x}, \pm)}{\partial t}=\left[D_{1 !} \frac{\partial^{2}}{\partial z^{2}}+D_{\perp}\left(\frac{\partial^{2}}{\partial x^{2}}+\frac{\partial^{2}}{\partial y^{2}}\right)\right] n(\vec{x}, t)+S(\vec{x}, t)
$$

where $n(\bar{x}, t)$ and $S(\vec{x}, t)$ are the density and source of injected particles, respectively. With this model the gradients in the background plasma are ignored and the gradients of the injected ions are those which drive the diffusion. The diffusion coefficient is determined by the interaction of the injected particles with the background plasma.

4 solution of the evolution of the impurity density can be determined by assuming that the source has the form,

$$
S\left(\bar{x}_{\mathrm{r}} t\right)=\delta(t) \exp \left[-\left(\frac{r^{2}}{r_{0}^{2}}+\frac{z^{2}}{z_{0}^{2}}\right)\right] \text {. }
$$

The impurity dansity then evolves as ${ }^{15}$

$$
n_{C}(\vec{x}, t)=\frac{K^{-}}{\left(D_{\|} t+\tau_{0}^{2}\right)^{\frac{1}{2}}\left(D_{\perp} t+r_{0}^{2}\right)} \exp -\left[\frac{r^{2}}{4 D_{\perp} t+r_{0}^{2}}+\frac{z^{2}}{4 D_{\|} t+\Sigma_{0}^{\frac{3}{0}}}\right],
$$

where the subscript $C$ signifies the injected carbon density, and $K$ is the overall calibration constant.

Because the spectrometer views a chord parallel to the symmetry axis of the plasma, the effect of the particles diffusing into the entire length of the viewing chord has been included in the computer code which calculates the expected density evolution accordinf to Eq. (3). This effect is not very important.

Figure 6 shows an example of the experimental and theoretical evolution of the injected CII density. For the theoretical calculation, constant values for the parallel and perpendicular difusion coefficients, and initial width were chosen. In addition, there is an overall multiplicative constant which represents the a-tual injected density. This constant is also kept fixed during the times shown in Fig. 6 and all of the panels have the same arbitrary units. For this calculaition, $D_{\perp}=1.5 \times 10^{5} \mathrm{~cm}^{2} / \mathrm{s}, D_{\|}=3.0 \times 10^{6} \mathrm{~cm}^{2} / \mathrm{s}$, and $r_{0}=z_{0}=0.6 \mathrm{~cm}$. 
In principle, this method of fitting the radial evolution of the test particle density to the calculated one could be used. Another methad which relies less on shot reproducibility, the exact linowledge of the parallel diffusion coefficient, or the initial width of the density, is to look at the temporal evolution of the carbon density at each radial location. Figure $i$ shows the temporal evolution density at various distances from the discharge. The solid line shows the experimentally observed evolution of the CII ions, while the dashed one shows the expected evolution from Eq. (3) for $D_{\|}=2 \times 10^{6} \mathrm{~cm}^{2} / \mathrm{s}, D_{j}=1.9 \times 10^{5} \mathrm{~cm}^{2} / \mathrm{s}$, and $z=0$.

To determine the perpendicular diffusion coefficient from a series of plasma shots with the same conditions and same injection time, the viewing optics is moved to various radial distances from the injection probe, $\Delta r$, and the temporal evolution of the injected particle density is observed at each location. At each position, a series of plasma shots is taken with and without particle injection. These shots are averaged together with the average of those shots without injection subtracted from those with injection. From this data, a delay time, $\Delta t$, is measured by determining the time points at which the signal is half its maximum value, $t_{1}$ and $t_{2}$. The measured 'time' for a given condition is simply halfway between, $t_{m}=\left(t_{2}+t_{1}\right) / 2$. The initial time of the carbon evolution, $t_{0}$, is then subtracted from the measured time to give a delay time, $\Delta t$, for the particular radius and conditions, $\Delta t=t_{m}-t_{0}$. The definition of the delay time is illustrated in Fig. 7. This method of determining the delay time was chosen for two major reasons, both shown in Fig. 7 . First, the delay time as described above changes much more significantly than the time of the peak expected signal. Secondly, it is sometimes very difficult to pick out the time of the peak signal, as the noise allows a number of peaks to be chosen. Figure 8 shows a theoretical calculation of the delay time, $\Delta t$, versus perpendicular diffusion coefficient at $\Delta r=1.5 \mathrm{~cm}$ and $\Delta r=3.0 \mathrm{~cm}$.

For a given plasma condition and firing time, a set of delay times is measured at the various observation points, $\Delta r$. The perpendicular diffusion coefficient is then determined by a least squares fit of these measured times to the expected times of various diffusion 
coefficients.

The paralle! diffusion coefficient can be measured by rotating the lens and fiber optic holder toroidally and viewing the arrival of the injected carbon ions along the flux tube onto which they were injected. Because of the finite pitch of the field lines the observed injected ions need not be at the same major radius as that at which they were injected, except for those injected at the magnetic axis. To correct for this, the lens assembly is scanned in major radius to find the radius at which the ions arrive earliest and which has the highest density of ions. It is at this position, that a delay time, $\Delta t$, is calculated to determine $D_{\|}$. For a plasma which is not moving, the shift in major radius can be used to measure the pitch of the feld lines and determine the safety factor, $q$.

\section{E. Fitting Technique and Error Analysis}

Because the equation for the delay time versus radits is not analytical, the least squares sum is determined by looping through the set of calculated delay times for each perpendicular diffusion coefficient. $\Delta t_{c}\left(\Delta r, D_{\perp}\right)$ and finding the value of $D_{\perp}$ which minimizes the sum

$$
M\left(D_{\perp}\right)=\sum_{i=1}^{n} \frac{\left[\Delta t_{m}\left(\Delta r_{i}\right)-\Delta t_{c}\left(\Delta r_{i}, D_{\perp}\right)\right]^{2}}{2.0 \sigma_{i}^{2}},
$$

where the sum is over the values of $\Delta t$ at the $n$ different radial observation points, and $\Delta t_{m}$ refers to the measured values. The variance, $\sigma_{i}$, is that of the experimental observations of $\Delta t$. The variance, $\sigma_{D}$, of the diffusion coefficient determined from the minimization of the sum in Eq. (4) can be estimated following Young. ${ }^{16}$ The minimization of Eq. (4) js equivalent to taking the derivative and setting it equal to zero,

$$
\frac{\partial M}{\partial D_{\perp}}=0=-\sum_{i=1}^{n} \frac{\left[\Delta t_{m}\left(\Delta r_{i}\right)-\Delta t_{c}\left(\Delta r_{i}, D_{\perp}\right)\right]}{\sigma_{i}^{?}} \frac{\partial \Delta t_{s}\left(\Delta r_{i}, D_{\perp}\right)}{\partial D_{\perp}}
$$

The variance of the fit is given by the second derivative of $\mathrm{Eq}$. (4),

$$
\frac{1}{\sigma_{D}^{2}}=\frac{\partial^{2} M\left(D_{\perp}\right)}{\partial D_{\perp}{ }^{2}}=\sum_{i=1}^{n} \frac{1}{\sigma_{i}^{2}}\left[\left(\frac{\partial \Delta t_{c}\left(\Delta r, D_{i}\right)}{\partial D_{\perp}}\right)^{2}-\left(\Delta t_{m}\left(\Delta r_{i}\right)-\Delta t_{c}\left(\Delta r_{i}, D_{\perp}\right)\right) \frac{\partial^{2} \Delta t_{c}\left(\Delta r, D_{\perp}\right)}{\partial D_{\perp}{ }^{2}}\right] .
$$


Equations (4) and (5) show the basic fitting technisgue used to reduce the experinsantal delay times into diffusion coefficients. A computer code is used to generate a set of delay times, $\Delta t_{c}$, for various $\Delta r$ 's and perpendicular diffusion coefficiests. At the rame time the first and second derivatives of the delay time with respect to $D_{1}: 1:$ also $s:$;cuiated. The experimental set of delay times versus radius is compared witk the sist .alculated witu the measured value of $D_{\perp}$, that which minimints the sum in $\mathrm{Eq}_{\mathrm{q}}$ (4). The error of the fit is then determined from Eq. (5).

The variances include those calculated from Eq. (5) and those which emanate from the uncertainties in the conditions of she model for the injected density evolation shown in Eq. (3). The two major parameters, other than $D_{\perp}$, are the initial width of the distribution, $r_{0}$, and the parallel diffusion coefficient, $D_{\|}$. An examisiation of Eq. (3) shows that at $z=0$ where the measurements of $D_{\perp}$ are made, the evolution of the carbon density should be less dependent on $r_{0}$ and $D_{\|}$than on $D_{\perp}$. A series of calculations of the deicy times versus radius were made for various values of $D_{\|}$, which varied from $1 \times 10^{6}$ to $3 \times 10^{6} \mathrm{~cm}^{2} / \mathrm{s}$ and $r_{0}$ which varied from 0.4 to $1.2 \mathrm{~cm}$. This range of parameters represents the experimental range and gives a $6 \%$ variance in the value of $D_{\perp}$ calculated, which is added in quadrature to $\sigma_{D}$ from Eq. (5).

In addition. it is necessary to determine the errors in the individual measurements of $\Delta t$. There are three primary sources of these errors, the uncertainty of the exact time from which the delay time should be calculated, errors in determining the delay time due to the fiuctuation level and the errors due to the reproducibility of the plasma. The latter two sources of error can be estimated by repeating the measurements of $\Delta t$ for the same experimental conditions. In addition, a series of measurements were taken with the same plasma conditions where the voltage on the capacitor was varied and in another case, the value of the capacitor was changed from $2 \mu \mathrm{F}$ to $1 \mu \mathrm{F}$. These measurements allow a variance of $\pm 3 \mu$ sec to be assigned to all data points, even if only a single sample was taken. Figure 9 shows an example of the fit of the calculated delay times to experimental ones for a case with $D_{\perp}=2.8 \pm 0.7 \times 10^{5} \mathrm{~cm}^{2} / \mathrm{s}$. 


\section{Effects of Ionization and Convection}

The last two effects to be included in the analysis of the perpendicular diffusion coefficient are the effects of convection and ionization on the injected particles.

Convection arises from the bulk motion of the plasma and the relative velocity across the flux surface. During the formation of the plasma, the magnetic axis starts in the flux core and siowiy moves into the plasma during the remainder of the formation. After the plasma is formed, the size shrinks due to the decay of the internal fields while the exterral field rensains constant. Thus, there is a continual shrinking of the plasma in the major radial direction. The velocity associated with this motion, which can be deternined from magnetic measurements, is typically less than $1 \times 10^{5} \mathrm{~cm} / \mathrm{s}$. The effect of the motion of the plasma, $v_{p}$, can be included in Eq. (3) by replacing $r$ by $r^{\prime} \equiv r-v_{p} t$.

The ionization of the injected carbon can be important. Until now the analysis has been carried out assuming that the carbon density cen be represented by the observed CII. This assumption is only valid as long as the ionization time of the carbon is long enough so that it can be ignored in the determination of the diffusion coefficients. All of the charge states $\mathrm{Cl}$ through CIV were observed in the injection discharge, though CII appears to be the dominant species. Immediately after injection all of the carbon is in the CII charge state. At later times, in some of the cases observed, there is some appearance of CIII in the plasma indicating that some ionization is occurring. Neither the CI nor CIV charge states appear above the noise level at any time after the initial discharge. Thus, it is assumed that all of the injected carbon is in the CII and CIII charge states and is initially in the CII charge state. The important effect on the evolution of the CII density is some ionization into the CIII charge state. This can be included in the model by using a characteristic ionization time, $\tau_{\text {ion }}$, dependent on the local electron density and temperature, for the CII to become CIII. The injected density evolution becomes

$$
n_{\mathrm{CII}}\left(r^{\prime}, t\right)=e^{-t / r_{\text {on }}} n\left(r^{\prime}, t\right)
$$


and

$$
n_{\mathrm{CIII}}\left(r^{\prime}, t\right)=\left(1-e^{-t / T_{\text {ion }}}\right) n\left(r^{\prime}, t\right)
$$

where $n_{\text {CII }}$ and $n_{\text {CIII }}$ are the densities of the CII and CIII charge states, and $n$ is the value calculated in Eq. (3). This characterization assumes either that CII and CIII diffuse at the same rate or that the amount of CIII in the plasma is not sufficient to change the CII gradients so that CIl continues to diffuse according to the initial assumptions.

Typically, the observed values of $\tau_{\text {ion }}$ estimated from the amount of time required to ionize injected impurities are greater than $40 \mu \mathrm{sec}$. These are roughly a factor of 2 larger tlan those expected from the average plasma electron temperature, ${ }^{17}$ but could be explained by a $25 \%$ drop in the local electron temperature due to the injection.

The effect on $D_{\perp}$ of changing $v$ and $\tau_{\text {jon }}$ has been examined. In the typical case where $\tau_{\text {ion }} Z 40 \mu \mathrm{sec}$ and $v \lesssim 1.0 \times 10^{5} \mathrm{~cm} / \mathrm{s}$, the effect on $D_{\perp}$ of changing $v$ and $\tau_{\text {jon }}$ is comparable to the variance calculated from the data as descrited in Sec. II. This is because the time scales for jonization and convection are longer than those associated with diffusion. The variance gets a little worse as the diffusion coefficient gets smaller, and the diffusion time scale gets longer.

It is difficult to determine either $v$ or $T_{i o n}$ exactly so that for the typical plasma conditions mentioned above a single value of each term will be used for the calculation of $D_{\perp}$. As long as it appears that $\tau_{\text {jon }} \geq 40 \mu \mathrm{sec}$ and $v \$ 1.0 \times 10^{5} \mathrm{~cm} / \mathrm{s}$, the values of $\tau_{\text {ion }}=60 \mu \mathrm{sec}$ and $v=5 \times 10^{4} \mathrm{~cm} / \mathrm{s}$ will be used. and a $15 \%$ error due to this technique will be added in quadrature to the errors described in the previous sections. This leads to a typical error in the nieasured value of $D_{\perp}$ of $20 \%$.

When either $\tau_{\text {ion }}$ or $v$ appears to be outside the limits mentioned above, the corrected values will be used in the calculation. The velocity, $v$, is determined from the magnetic measurements, and $\tau_{\text {ion }}$ can be estimated by the appearance of a significant. CIII signal. An example of a case with a small value of $\tau_{\text {ien }}$ is illustrated in Fig. 10. For this case: the solid lines are calculated for $\tau_{\text {ion }}=10 \mu \mathrm{sec}, D_{\perp}=1 \times 10^{5} \mathrm{~cm}^{2} / \mathrm{s}, v=1 \times 10^{5} \mathrm{~cm} / \mathrm{s}$, and $D_{\left.\right|_{i}}=3 \times 10^{6} \mathrm{~cm}^{2} / \mathrm{s}$. The poor quality of the fit may be due to a changing $\tau_{\text {ion }}$ during 
the period observed. The CII density evolution can be better fit with a slightly longer ionization time or a slight]y different diffusion coefficient.

The errors in the measurement of $D_{\|}$are larger than those of $D_{\perp}$ for two important reasons. The first reason was described above: there is more uncertainty in the measurement of $\Delta l$ than in $\Delta r$. The latter can be directly measured, but the former requires a knowledge of the local $g$. A second important source of error is that only a single value of $\Delta \phi$ can be observed due to the constraints imposed by the machine and diagnostic design. A value of $\Delta \phi$ twice as large as the one used for the measurement is allowed but the signal level is too small at this distance from the discharge. The signal can be observed at both positive and negative $\Delta \phi$, and these signals have similar shapes.

\section{TV. Results in the Afterglow Plasma}

During the period after the disappearance of the internally generated magnetic fields of the plasma, the density decays in the slightly mirrored externally applied verti al field. This period is known as the afterglow plasma. For the case examined, the vertical field strength is $300 \mathrm{G}$, and the electron density and temperature were roughly $2.5 \times 10^{13} \mathrm{~cm}^{-3}$ and $3 \mathrm{eV}$; respectively.

The advantage of looking at the afterglow plasma is that it is electrically quiet, giving accurate results with the triple probe, This plasma provides a good test of the method because at this time the temperature and density are uniform and there is no motion of the magnetic field.

Because the electron density changes on a time scale comparable to the transport time scale, the spectroscopic signal is divided by the electron density. Figure 11 shows the evolution of the injected CII density at various distances from the discharge which was at $t_{0}=156 \mu \mathrm{sec}$. The data have been averaged over $\pm 4 \mu \mathrm{sec}$ around the plotted data point.

The solid lines in Fig. 11 are those calculated from Eq. (3) assuming $D_{\perp}=1.8 \times$ $10^{5} \mathrm{~cm}^{2} / \mathrm{s}$ and $D_{\|}=2.0 \times 10^{5} \mathrm{~cm}^{2} / \mathrm{s}$. In this geometry, the magnetic field is parallel to the $\vec{z}$ direction so that the $\vec{R}$ direction is still perpendicular to the magnetic field. With the 
small magnetic field, there is very little difference between $D_{\perp}$ and $D_{k}$.

In the afterglow plasma, the classical perpendicular diffusion coefficient is varying and is given approximately by $D_{1}=3 \pm 1.5 \times 10^{5} \mathrm{~cm}^{2} / \mathrm{s}$. The determination of the classica] diffusion coefficient is discussed in the appendix. This shows that the method of measuring the particle diffusion coefficient does a good job of producing the expected classical results within the uncertainties of the measured quantities.

Both perpendicular and parallel diffusion coefficients can be measured locally with errors less than $30 \%$. With this method the diffusion coefficients can be mapped out and related to various plasma quantities to better understand the transport processes in the plasma.

\section{Acknowledgments}

We would like to thank M. Yamada, R.J. Goldston, and R.A. Hulse for many fruitful discussions, and S. Paul for the use of a spectrometer and fiber optic casle. This work appears as part of the doctoral dissertation of one of us (D.D.M.) and was supported by the U.S, Department of Energy Contract No. DE-AC02-76-CHO3073. 


\section{Appendix A. Classical Diffusion Coefficient in the Afterglow Plasma}

The carbon-hydrogen collision time, $\tau_{i}$, and diffusion coefficient can be calculated assuming that the hydrogen density and temperature are the same as those of the electrons. The electron density and temperature evolutions as measured by a Triple Langmuir Probe are shown in Fig. 12.

The ion collision time is ${ }^{14}$

$$
\tau_{i}=1.8 \times 10^{8} \frac{T^{1.5}}{n_{H !} \ln (\lambda)} \mathrm{sec}
$$

where $\ln (\lambda)$ is the coulomb logarithm, ${ }^{18}$ and is about 9 for these plasmas. In the afterglow plasma, $\tau_{i}$ is roughly $2 \times 10^{-6} \mathrm{sec}$, and the ion cyclotron frequency, $\Omega_{i}$ is roughly $2,4 \times$ $10^{5} \mathrm{rad} / \mathrm{sec}$ so that the product, $\Omega_{i} \tau_{i}$ is less than 1 and the ions are basically unconfined by the magnetic field.

The classical perpendicular diffusion coefficient can be calculated according to Chen, ${ }^{19}$

$$
D_{\perp}=\frac{D_{\|}}{1.0+\left(\Omega_{i} \tau_{i}\right)^{2}}
$$

The parallel diffusion coefficient, $D_{\|}$, is determined by the collisional mean-free path and collision time. ${ }^{18}$

$$
D_{\|}=\frac{v_{i}^{2} \tau_{i}}{2.0}
$$

In the afterglow plasma, the classical perpendicular diffusion coefficient is varying and is given approximately by $D_{\perp}=3 \pm 1.5 \times 10^{5} \mathrm{~cm}^{2} / \mathrm{s}$. 


\section{References}

${ }^{1}$ M. Yamada, R. Ellis, Jr., H. P. Furth, R. Hulse, A. Janos, S. C. Jardin, D. McNeill, C. Munson, M. Okabayashi, S. Paul, D. Post, J. Sinnis, C. Skinner, Y. C. Sun, F, Wysocki, C. Chin-Fatt, A. W. DeSilva, G. C. Goldenbaum, G. W. Hart, R. Hess, R. S. Shaw, C. W. Barnes, I. Henins, H. W. Hoida, T. R. Jarboe, S. O. Knox, R. K. Linford, J. Lipson, J. Marshall, D. A. Platts, A. R. Sherwood, and B. L. Wright, in Plasma Physics and Controlled Nuclear Fusion Research: 1982, Baltimore Conference, Vol. 2, p. 265 (1AEA, Vienna, 1983).

${ }^{2}$ D. Dimock, D. Eckhartt, H. Eubank, E. Hinnov, L. Johnson, E. Meservey, E. Tolnas, and D. Grove, in Plasma Physics and Controlled Nuclear Fusion Reseanch, 1971, Volume 1 (Madison Conference), p. 451 (IAEA, Vienna, 1971).

${ }^{3}$ L. C. Johnson and E. Hinnov, J. Quant. Spectrosc. Radiat. Transfer 13, 333 (1973).

${ }^{4} J$. Strachan, N. Bretz, E. Mazzucato, C. Barnes, S. Cohen, J. Hovey, R. Kaita, S. Medley, B. Schmidt, G. Tait, and D. Voss, Nucl. Fusion 22, 1145 (1982).

${ }^{5}$ A. Bagdasarov, N. Vasin, V. Vershkov, N. Gegechkori, V. Zhurvief, Y. Karzhavin, A. Pimenov, V. Sirizhov, V. Trukhin, S. Egorov, B. Kuteev, and V. Sergeev, in Plasma Physics and Controlled Nuclear Fusion Research, 1984, p. 181 (IAEA, Vienna, 1985) [Vol. I(London conference)].

${ }^{6}$ R. A. Hulse, Nucl. Technol./Fusion 3, 259 (1983).

${ }^{7}$ E. Marmar, J. Cecchi, and S. Cohen, Rev, Scj. Instrum. 46, 1149 (1975).

${ }^{8}$ E. Hinnov, S. Suckewer, S. Cohen, and K. Sato, Phys. Rev. A 25, 259 (1982).

${ }^{9}$ R. Fonck, M. Finkenthal. R. J. Goldston, D. Herndon, R. A. Hulse, R. Kaita, and D. D. Meyerhofer, Phys. Rev. Lett. 49, 737 (1982).

${ }^{10}$ R. Stern, D. Hill, and N. Rynn, Physics Letters 93A, 127 (1983). 
${ }^{11}$ S. Takamura, N.Ohnishi, K. Iwai, and T, Okuda, Phys. Rev. Lett. 56, 2044 (1986).

${ }^{12}$ C. Pitcher, G. McCracken, J. Allen, D. Goodall, G. Matthews, and P. Stangeby, in 7th International Confenence on Plasma-Surface Interactions in Contralled Fusion Devices (Princeton Plasma Physics Lab, Princeton, NJ, 1986).

${ }^{13}$ H. Price, H. Garner, and H. lkezi, Technical Report GA-A17772, GA Technologies (1985).

${ }^{14}$ F. L. Hinton, in Handbook of Plasma Physics, Vol. 1 Basic Plasma Physics, edited by A. Galeev and R. N. Sudan, p. 148 (North-Holland Publishing Co., Amsterdam, 1983).

${ }^{13}$ P. M. Morse and H. Feshbach, Methods of Theoretical Physics (MeGraw-Hill, New York, 1953).

${ }^{16} \mathrm{H}$. Young, Statistical Treatment of Experimental Data (McGraw-Hill, New York, 1962).

${ }^{17}$ K. Bell, H. Gilbondy, J. Hughes, A. Kingston, and F. Smith, Technical Report CLMR216, Culham Laboratory (1982).

${ }^{18}$ S. Braginskii, Transport Processes in a Plasma, Volume 1 of Reviews of Plasma Physics (Consultants Bureau, New York, 1965).

${ }^{19}$ F. Chen. Plasma Physics and Controlled Fusion, Volume 2 (Plenum Press, New York; 1984). 


\section{Figures}

FIG. 1. Basic experimental setup.

FIG. 2. Details of the injection probe construction.

FIG. 3. Photograph of the injection probe.

FIG. 4. Typical current trace in the injection circuit.

FIG. 5. Example of the impurity density profile at the end of the injection discharge.

FIG. 6. Experimental and theoretical evolution of the injected CII density versus radius at $4 \mu \sec (a), 8 \mu \sec (b), 12 \mu \sec (c), 16 \mu \sec (d), 20 \mu \sec (e)$, and $24 \mu \sec (f)$.

FIG. $\tau$. The experimental (solid) and calculated (dashed) temporal evolution of the injected CII ions at $\Delta r=1.5 \mathrm{~cm}(\mathrm{a}), 2.0 \mathrm{~cm}(\mathrm{~b})_{5}$ and $2.5 \mathrm{~cm}(\mathrm{c})$.

FIG. 8. Calculated delay time, $\Delta t$; versus perpendicular diffusion coefficient at $\Delta r=$ $1.5 \mathrm{~cm}(\mathrm{a})$ and $\Delta r=3.0 \mathrm{~cm}(\mathrm{~b})$.

FIG. 9. The fit of the calculated values of $\Delta t$ to the measured values for a case with $D_{\perp}=2.8 \pm 0.8 \times 10^{5} \mathrm{~cm}^{2} / \mathrm{s}$.

FIG. 10. Observed and calculated evolutions of the CII and CIII density for $\tau_{\mathrm{ian}}=10 \mu \mathrm{sec}$ at $\Delta r=2.0 \mathrm{~cm}(\mathrm{a}, \mathrm{b}) . d l r=2 . \overline{\mathrm{cm}}(\mathrm{c}, \mathrm{d})$, and $\Delta r=3.0 \mathrm{~cm}(\mathrm{e}, \mathrm{f})$.

FIG. 11. Evolution of the CII density in the afterglow plasma at $\Delta r=4 \mathrm{~cm}(\mathrm{a}), \Delta r=$ $6 \mathrm{~cm}(\mathrm{~b})$, and $\Delta r=8 \mathrm{rm}(\mathrm{c})$. The solid lines are the calculated evolutions for $D=$ $1.8 \times 10^{5} \mathrm{~cm}^{2} / \mathrm{s}$.

FIG. 12. Evolution of the elertron density(a) and electron temperature(b) in the afterglow plasma. 


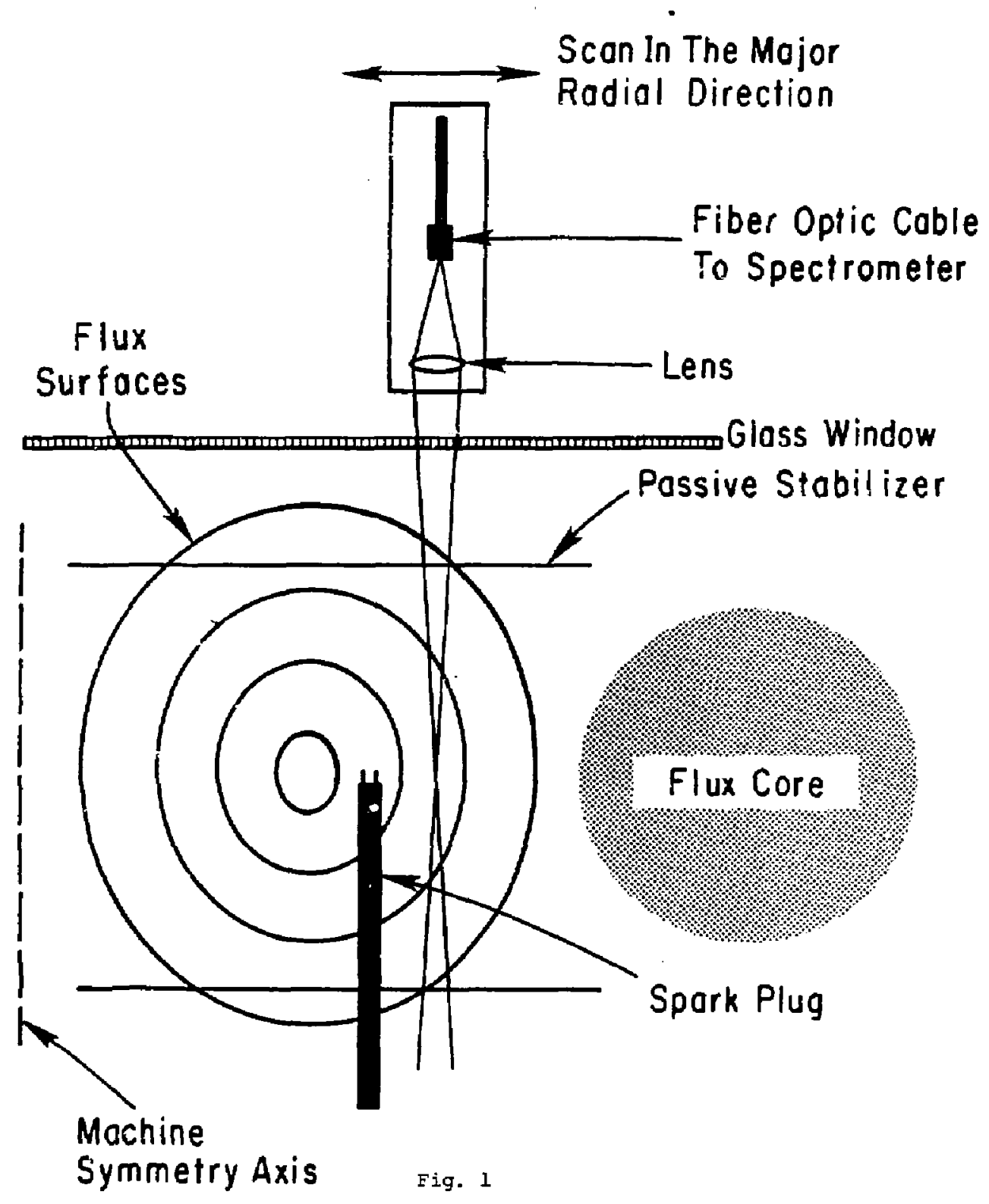




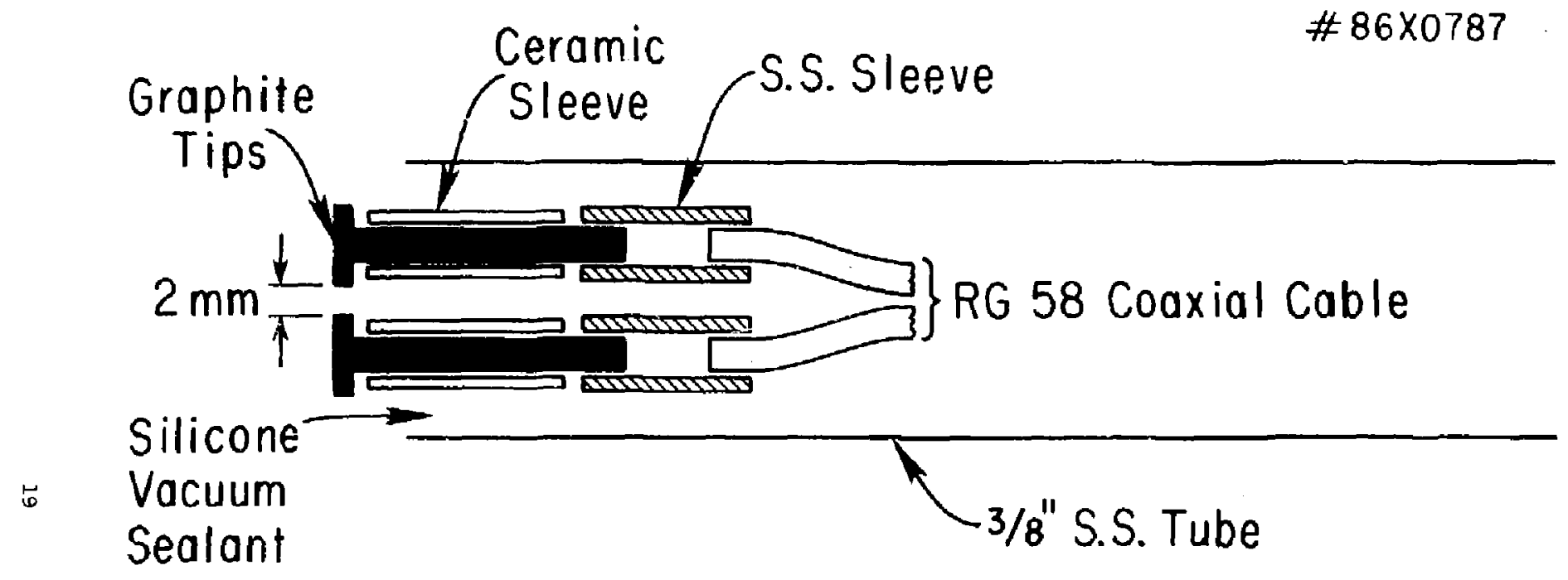



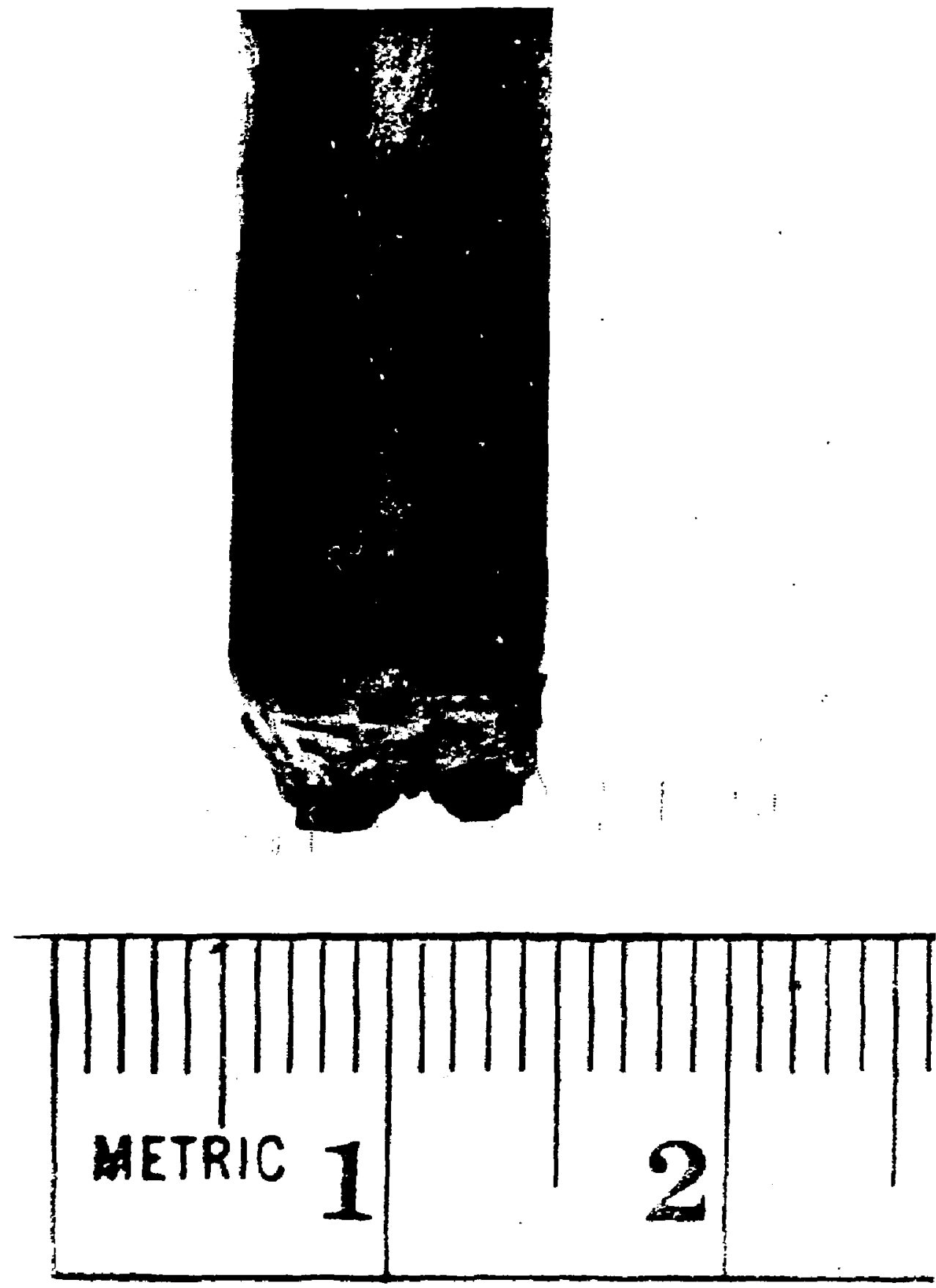

Fig. 3 


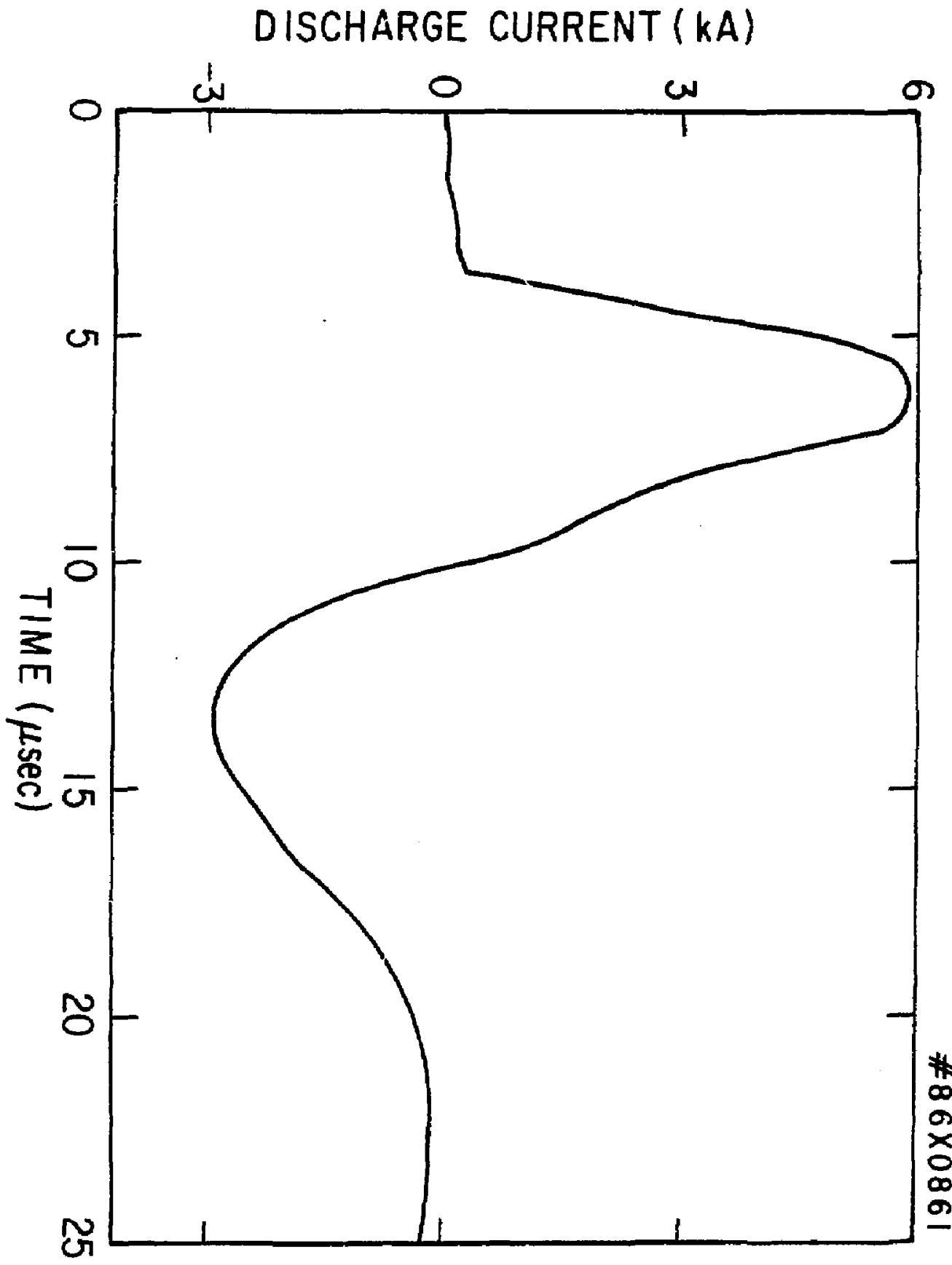




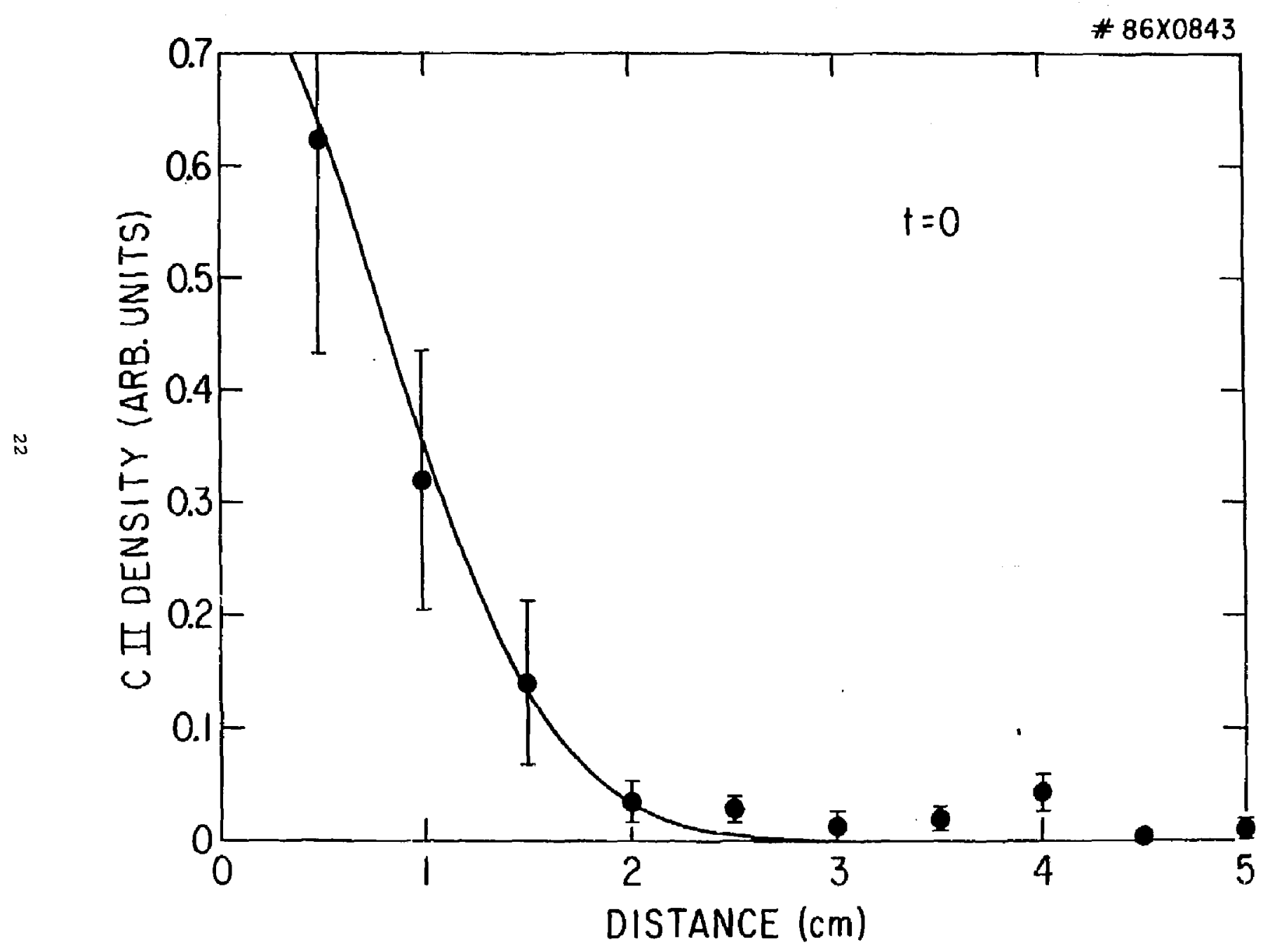

Fig. 5 

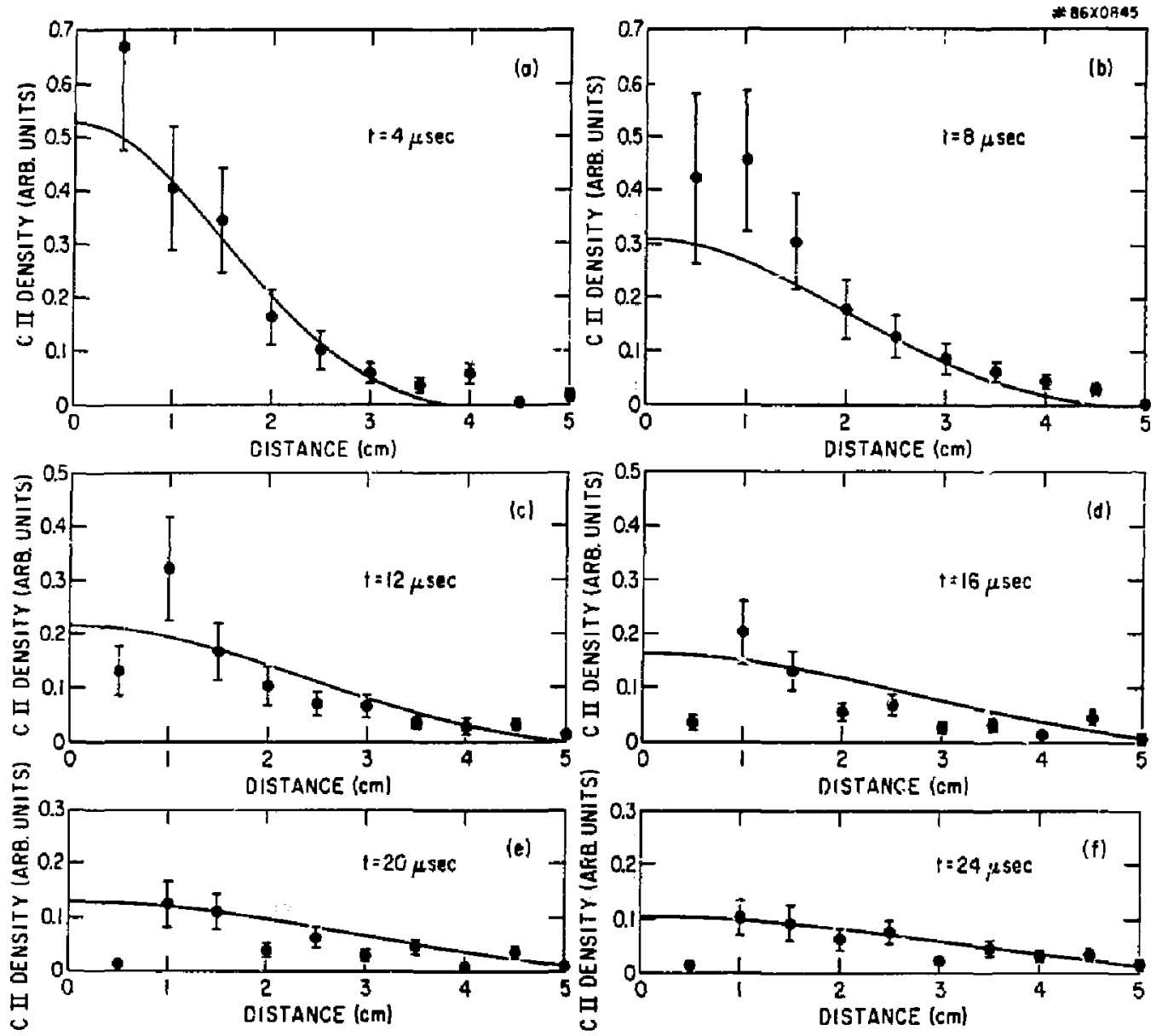

Fig. 6 

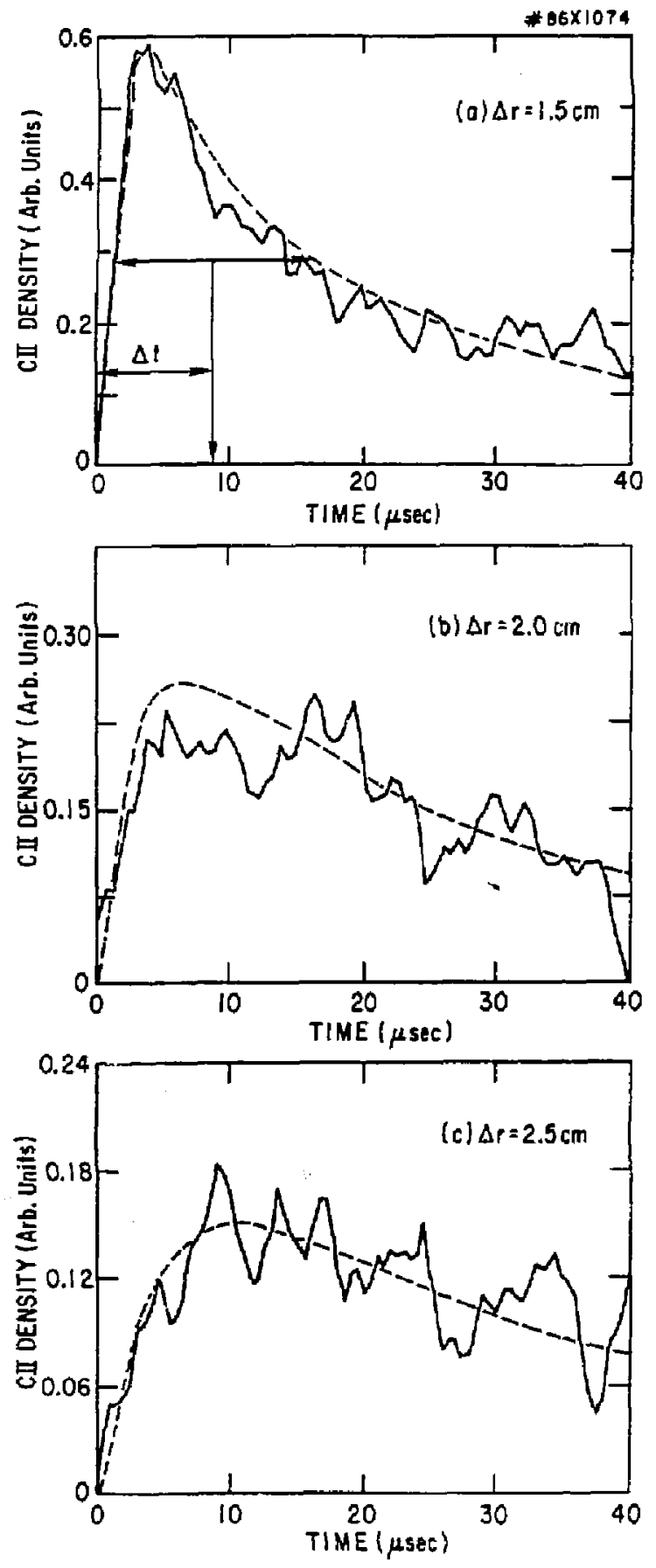

Fig. 7 

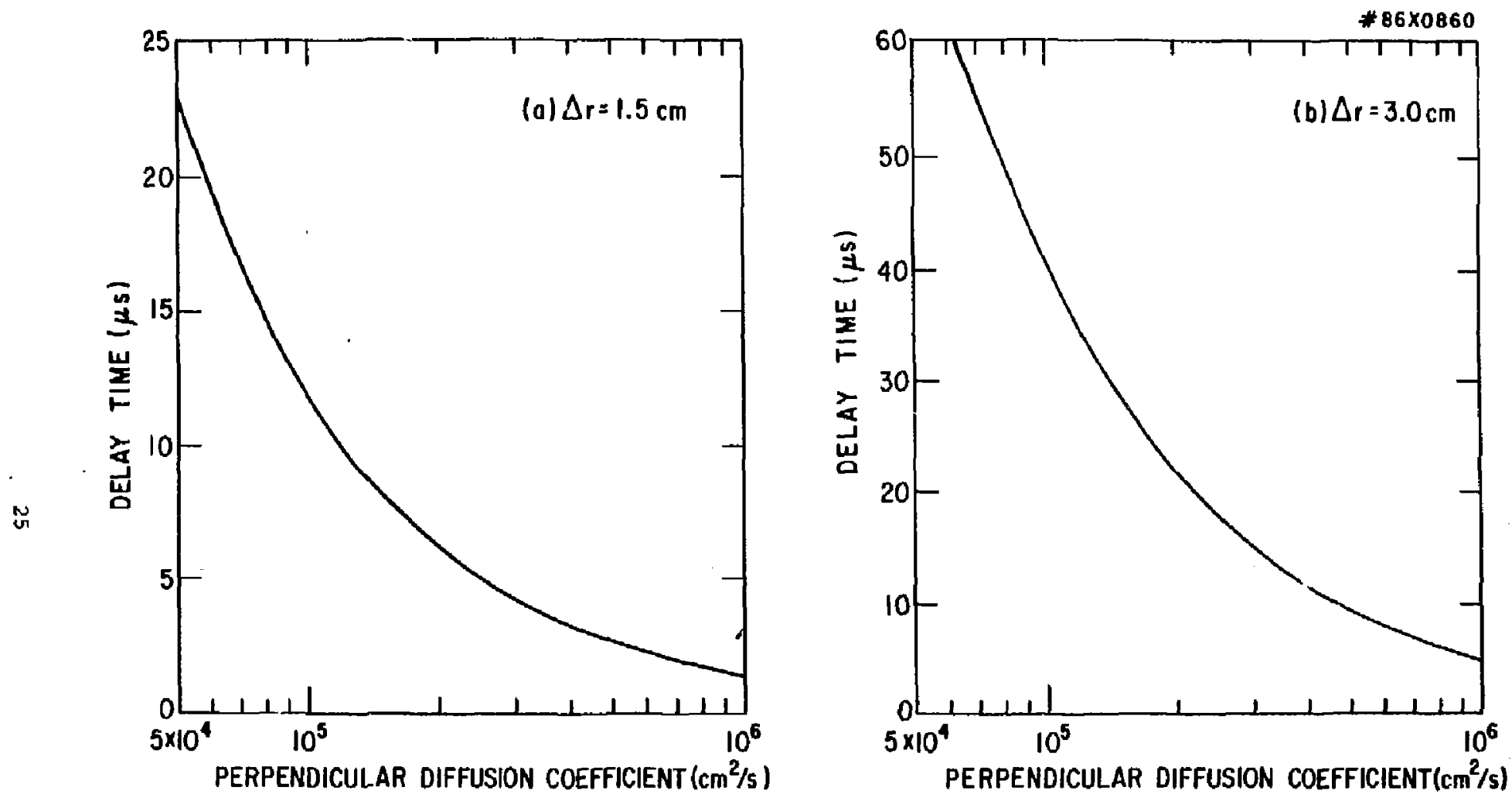


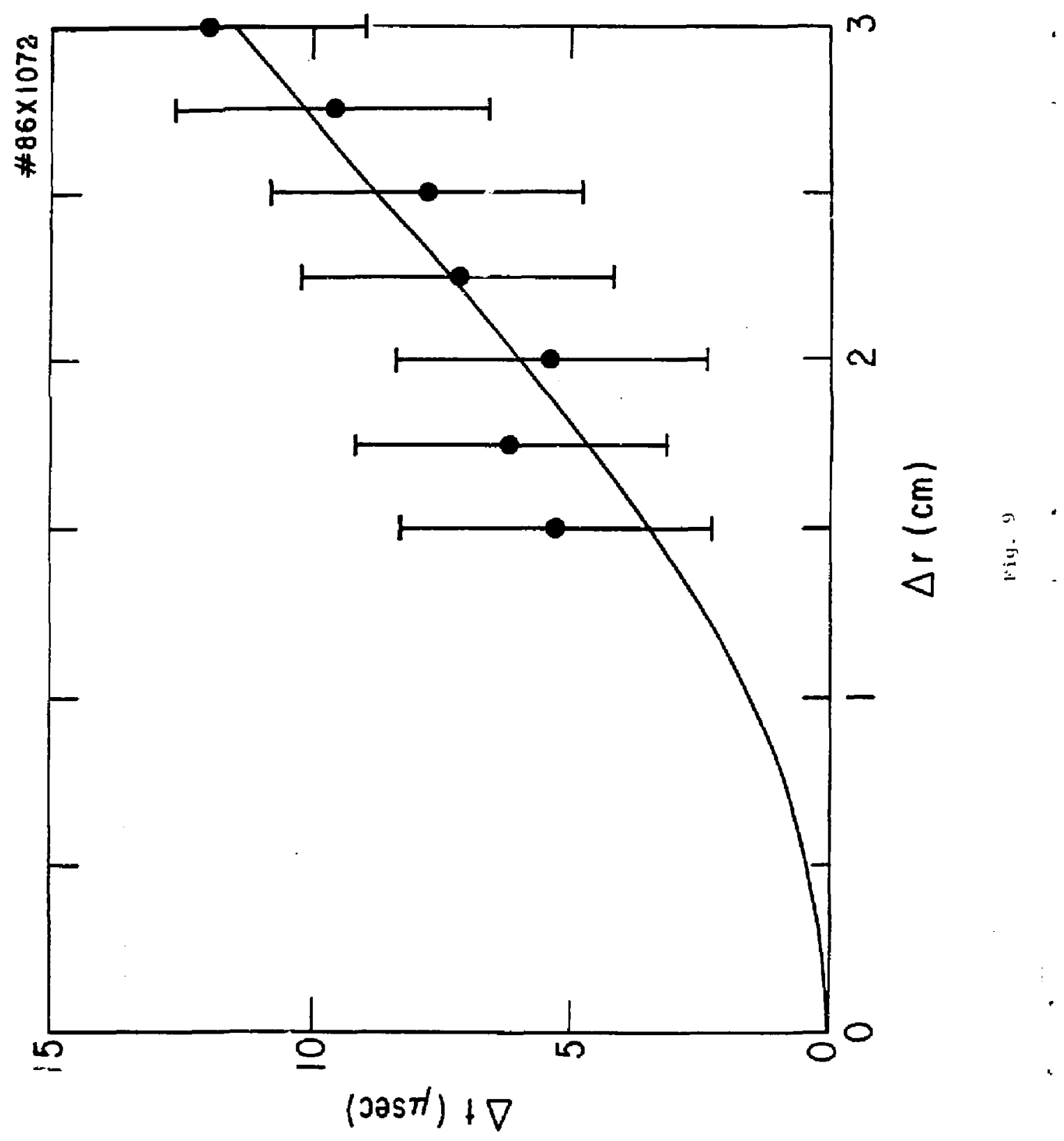



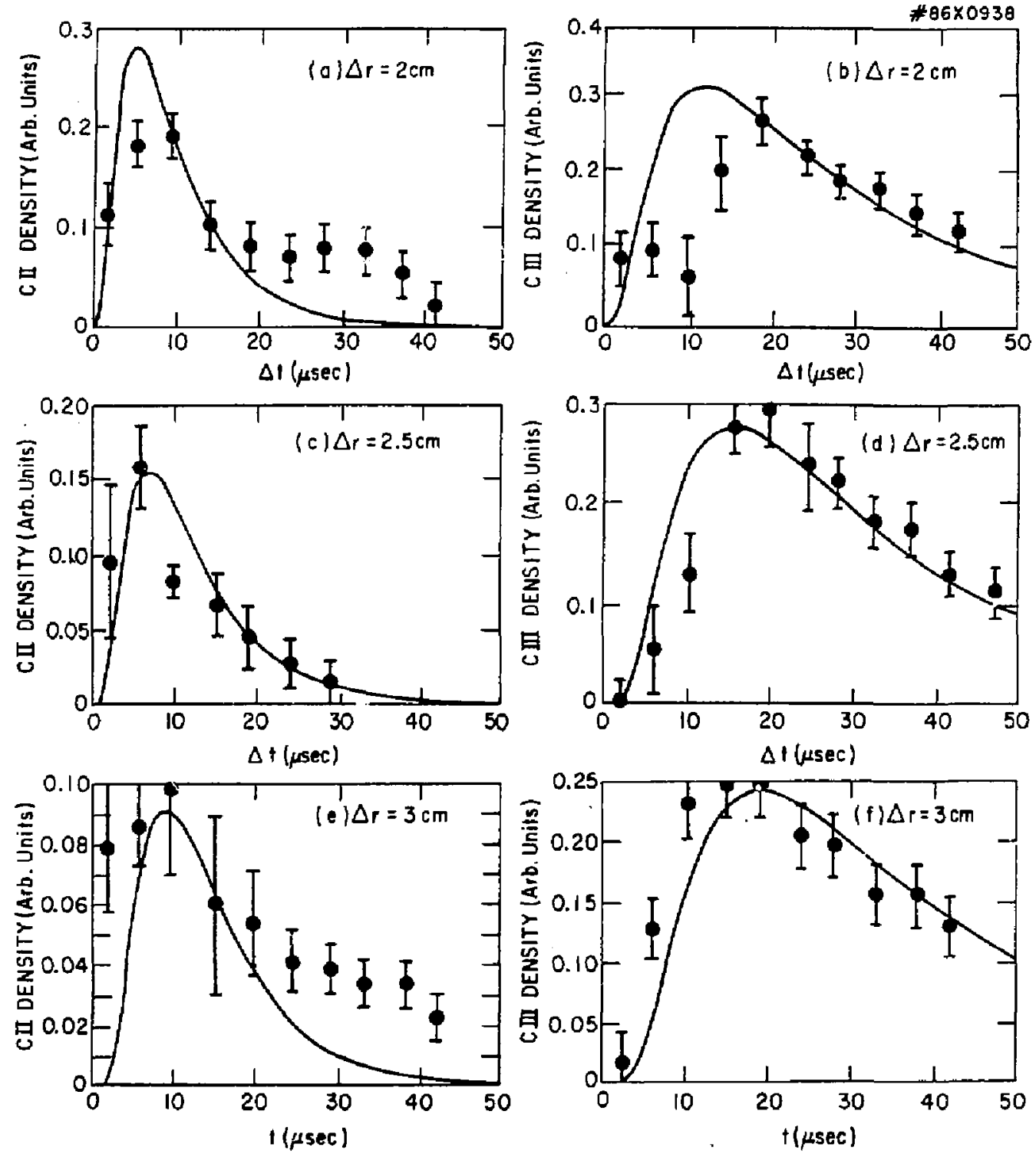

Fig. 10 

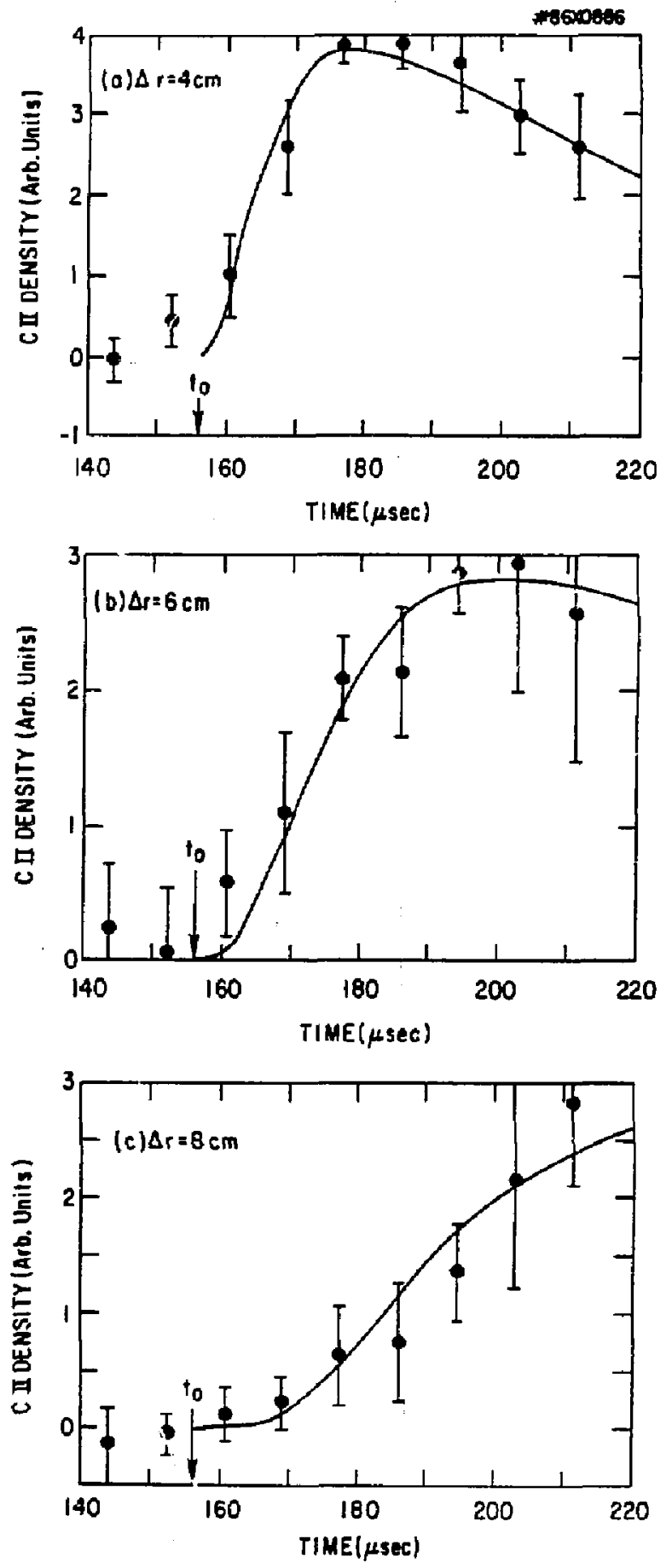

Fig. 11 


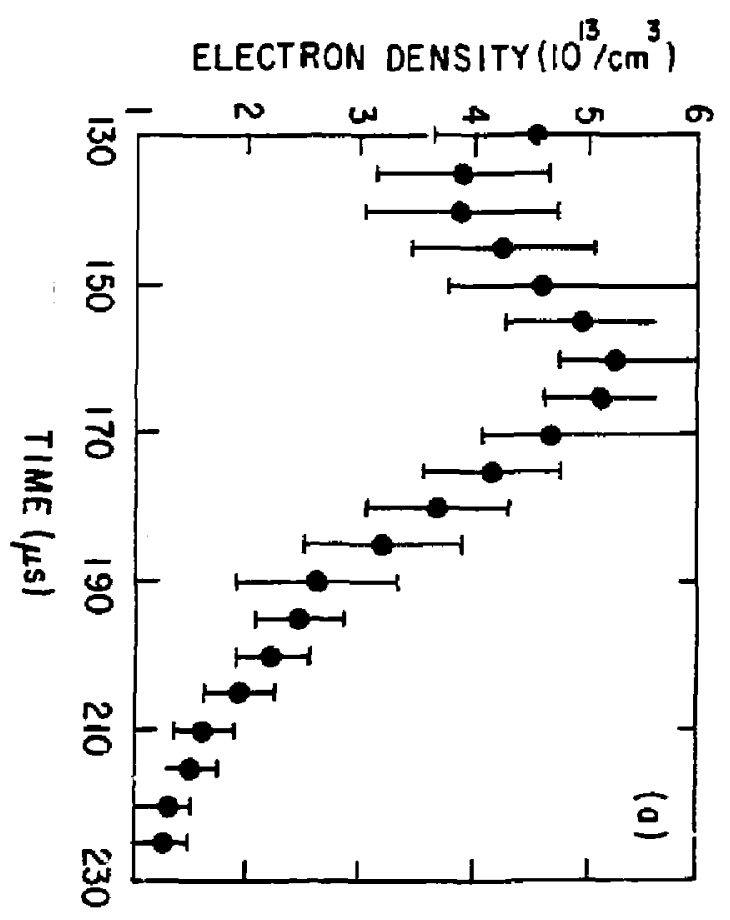

范
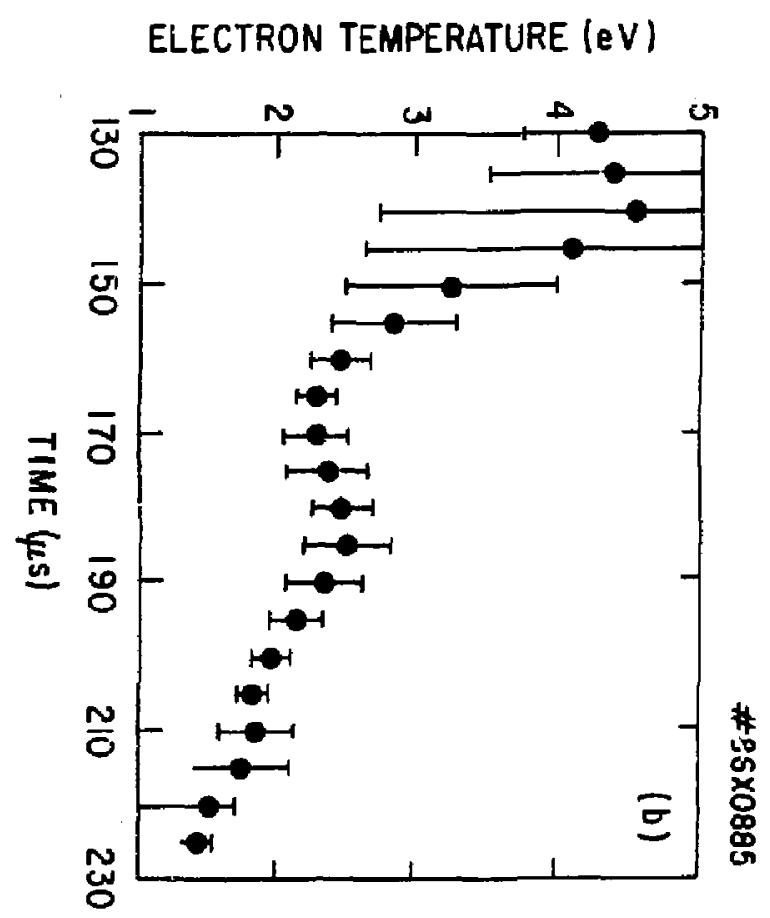
Dr. Frank J, Paolonl, Unlv of wa:longong, AUSTRALIA Prot. M.H. Broman, Unlv Sydney, NUSTRMLIA Plasine Resagrch Lab.. Australian Nat. UnIV.. AUSTRMLIA Prot. I.R. Jones, fllinders Untr. , NUSTRMLIA

Prot. F. Cap, Inst Theo Phys, NUSTRIA

Prof. M. Hoindler, Institut fur Theorotische PhysIk, wSIRIA

M. Goossons, Astronomisch Instituut, BELGILM

Ecale Roysle Milltalre, Lab de Phys Plsamas, BelgilM

Com. of European, Dg Xil Fusion Prog, BELGIUM

Prof, R. Bouclque, Laboratorlum yoor Natuurkunde, BELGIUH

Dr. P.H. Sakanaka, UnIY Estadual, ERAZli

Instituto on Pesqulsas EsdaclasI-INPE, BRAZIL

LIbrary, Atomile Energy of Canada Linited, CANADA

Dr. M.P. Bachynski, MPB Technologles, Inc., CANAOA

Dr. H.M. Skarsgard, UnIV of Saskatchewan, CANMOA

or. H. Bornard, University of British Columbla, GNAOA

Prof. J. Telchmann, Unly. of Montreal, CANADA

Prof. S.R. Sroanivasan, University of Colgary, CANAOA

Prot. Tudor $W$. Johnston, InS-Energle, CANADA

Or. CA. Jomes, UnTY, of Alberta, CAMNOK

Dr. Petur Lukec, Komensticho UnIV, CZECOOSLOVAXIA

The Librarlan, Culha Laborstory, ExiNAD

wrs. S.A. Hutchinson, JET LIbrary, EMGLND

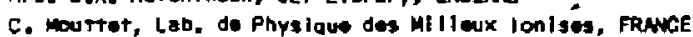

J. Rader, CEH/CNDARACHE - Bar 506, FRANCE

Dr. Tow Mul, Academy glbliographle, HOHG KONG

Preprlat Library, Cent Res Inst Phys, Hughar

Dr. B. Dasgupto, Sand Inst, InDIA

Dr. R.K. Chajlanl, VIkram UnIv. IMalA

Dr. P. Kon, Institute for Platema Roscarch, IRDIA

Dr. PhIllip Rosenau, l sräl Inst Tech, ISRAEL

Prof. 5. Cuperman, Tel AvIY Unlveralty, I5RAEL

Librarlan, Int'l Ctr Theo Phys, ITALY

Prot, G, Rostagni, UnIv ol Padova, ITALY

MIss clello De Fulo, Aseoc ELRATOM-ENEA, ITALY

Blbllotece, del OHR EURATOM. ITALY

Or. H. Yamato, Toshiba Re 1 Oow, JAPN

Pret. 1. Kawakeal, Atomle Energy Res. Institute, JAPAY

Prot. Kyojt Mishtkawe. Unly of Hiroshles, JAPAN

Dlrec. Dept. Lg. Tokenek Res. JAERI, JAPAW

Frof. Sutoshi itoh, Kyushu University, JAPAM

Research Info canter, Magoye University. IAPAM

Prst. S. Tencka, Kyoto University, JAPN

. lorery, Kyoto Unlversity, JNPAN

prot. Nobuyukl Inowe, UnIverstty of Tokyo, JAPAH

5. MorI, JAERI, JAPNY

M.H. KIm, Kores Advanced Energy Resurch Institute, KOREA Prof. D.1. Chol, Adv, Inst Sel \& Tweh, KOREA

Prof. 9.5. LIIEY, University of walkoto, MEW ZEN,AMO

Institute of PIasm Physlos, PECPLE's aepubLIC of CHIMA

Llorarlan, Institute of PhYs., Nenteles REDULIC OF CHINA

Library, Tsing Hu UnlyersIty, PEOPLE'S REPUBLIC OF CHIHA
2. LI, Southmest Inst, Physlgs, PEOPLE'S REPUELIC OF CHINA Prof, J.A.C. Cobral, Inst Sugerfor Twen, PORTUGAL Dr. Octarian Petrus, AL I CuZA University, ROMANIA Dr. Johan de villiera, Plasmo Physics, AEC, SO AfRICA Prot. M.A. Helloerg, Unlversity of Natal, SI AFRiCA Fusion DIV. LIbrary, JEN, SPAIN

Or. Lennart Stenflo, Unlyarslty of LWEA, SWEDEN Llbrary, Royal inst Tech, JWEeN

Prot, Hans wilhelmon, Chalmars Unly Teen, SWEDEN Centre Phys des Plasmas, Ecole Polytech Fod, SWITZERLAND glbilotheak, Fom-inst Yoor Plasme-Fysica, THE NETHERLANDS Dr. D.D. Ryutov, SIberlan Acad SCf, USSR

Dr. G.A. EIIsew, Kulchatov Institute, USSR

Dr. $V, A$, GlukhIkh, Ingt Electro-Phys Ical, USSR

Dr. V.T. Tolok, Inst. Phys. Toen. USSR

Dr. L.M. KourIzhnykh, Institute Gen, Physles, USSR

Prof. T.J.M. Boyd, UnIY College N Wales, WhLES Nuclear Res. Establishment, Jullach LTd., W, GERMANY Blbllothel, Inst. Fur Plasmaforschung, W. GERMAYY Or. K. Sehindler, Ruhr Univorsita:, W. GERuy ASDEX Rooding Ran, IPP/Max-PIanck-1 astItut fur Plaseaphystk, W. GePuhr LIbrartan, Moxplonek institut, W. GERMANY Prof. R.K. Jenov, Inst Phys, YugoslaviA 